\title{
Drug facilitation of memory in rats'
}

\author{
Lewis Petrinovich, STATE UNIVERSITY OF NEW YORK, STONY BROOK \\ Donald Bradford, SAN JOSE STATE COLLEGE \\ James L. MeGaugh, UNIVERSITY OF CALIFORNIA, IRVINE
}

\begin{abstract}
Abstraet
Rats from the RCL and RDL strains were administered strychnine each day after either the first or second of four trials on a delayed alternation problem. With long intertrial delays the strychnine injected Ss performed significantly better than control Ss on the trials following the injection.

\section{Problem}

There is increasing evidence that, in rats, memory storage can be enhanced by drugs (McGaugh \& Petrinovich, 1965). In all of the studies on this problem to date the tasks were conventional learning tasks including mazes and visual discrimination problems in which the rats had to learn the relevance of environmental cues. The findings (e.g., Breen \& McGaugh, 1961; Stratton \& Petrinovich, 1963) that drugs can influence memory storage when they are administered within a short period after training trials support the interpretation that the drugs influence memory by acting on processes that are initiated by training and which perseverate for some period after the training trials have ceased.

As a further test of this general hypothesis the present study investigated the effect of strychnine sulphate on a task-delayed response alternation-in which the correct response on any test depends upon the rat's response on the preceding trial. In previous work Petrinovich \& Bolles (1957) found that rats were able to perform a delayed response alternation with intertrial intervals as long as 5-1/2 hr., but that accuracy declined with longer intervals. They suggested that the cue for the correct response is the rat's memory of its choice on the preceding trial.

The findings of the present study indicate that strychnine improves rats' performance on a delayed alternation task and, consequently, provides additional evidence that strychnine enhances memory processes.

\section{Subjeets}

The Ss were 20 male, adult rats: 10 from the RDL strain and 10 from the RCL strain. These strains were obtained from the University of California, Berkeley psychology laboratories and were genetically selected (Roderick, 1960) on the basis of low cerebral cortex acetylcholinesterase activity.

\section{Apparatus}

The maze was a single-unit elevated $\mathrm{T}$ with a main stem $173 \mathrm{~cm}$ long and arms $61 \mathrm{~cm}$ long. The two goal boxes were $25 \mathrm{~cm}$ square x $28.5 \mathrm{~cm}$ high with a black cloth curtain hung just inside the door. The starting box and both goal boxes were fitted with guillotine doors. The two goal boxes could be fitted with drinking tubes. The entire apparatus was painted a flat black.

\section{Procedure}

Lethal dosage study: Prior to the beginning of maze testing a study was made of the lethal dosage for strychnine with these two strains of rats. Since the results were almost the same for each strain they were combined. The MLD was found to be $2.5 \mathrm{mg} / \mathrm{kg}$. The $\mathrm{LD}_{50}$ was about $3.5 \mathrm{mg} / \mathrm{kg}$ and the $\mathrm{LD}_{100}$ was about $4.0 \mathrm{mg} / \mathrm{kg}$.

Preliminary training: A Verplanck-Hayes water deprivation schedule (1953) was used throughout the experiment. Each day, water, but no food, was available for $22 \mathrm{hr}$. One $\mathrm{hr}$. before the Ss were run in the apparatus the water was removed and Ss were given dry food pellets, but no water. Water was restored to the cages after the last trial on each day. The amount of food was adjusted to stabilize the Ss weights at $70 \%$ of their pre-experimental body weight.

Each $\mathrm{S}$ was given water in a replica of the goal box for $5 \mathrm{~min}$. on each of two days. Starting on the third day each $\mathrm{S}$ was run three times a day on a straight-away into the goal box from progressively greater distances. Each was allowed to drink for $20 \mathrm{sec}$. on each trial. During this period the black curtain in the goal box was progressively lowered on each day and the animal had to run through it. On the eighth to thirteenth day each $\mathrm{S}$ was run from the starting box three times a day.

Maze training: Phase I. The Ss were given three trials per day using the noncorrection method. They were allowed to drink for $20 \mathrm{sec}$. after a correct response and were detained for $20 \mathrm{sec}$. in the empty goal box after an incorrect response. The first trial of each day was rewarded no matter which side $\mathrm{S}$ chose. On the second trial the reward was on the side opposite that chosen on the first trial. On the third trial the reward was on the side opposite that which S chose on the second trial, whether or not trial two was correct. Thus, a position habit would result in only one rewarded response each day.

Each $\mathrm{S}$ was injected intraperitoneally immediately after the first and second trials with either $1.0 \mathrm{mg} / \mathrm{kg}$ body weight of strychnine sulphate or with normal saline. The order of the injections was randomly determined. Thus, on some days $S$ received an injection of strychnine following trial one and on some days an injection of saline. Following trial two those Ss which previously had received a saline injection were given a strychnine injection, while those which had received a strychnine injection were given a saline injection.

On day 11 of Phase I those Ss which were performing at a very low level were dropped from the experiment. The Ss which were retained (six RDL and eight RCL) 


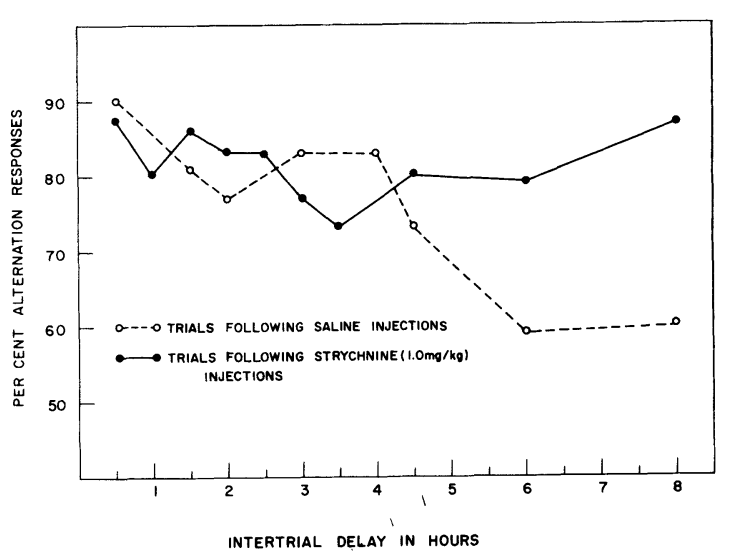

Fig. 1. Per cent alternation responses of Ss on trials following strychnine or saline injections.

were trained for five more days. These 14 Ss had, therefore, a total of 16 days training in Phase $I$.

Delayed intervals: Phase II. The 10 Ss (five of each strain) which achieved the best alternation scores were run in this phase of the experiment.

Each $\mathrm{S}$ was run three times per day for six days at each of 10 intertrial intervals. The intervals used were $1 / 2,1,1-1 / 2,2,2-1 / 2,3,3-1 / 2,4-1 / 2,6$, and $8 \mathrm{hr}$. The randomized, counterbalanced order of strychnine and saline injections was the same for each of the six-day intervals.

\section{Results}

Since the effects of strychnine injected on trial two would not have completely disappeared by trial three, the results on trial two only are presented here.

Phase I. The performance of the Ss for the first 11 days when all Ss were being run indicated that Ss of the RCL strain performed at a higher level (proportion of responses correct: $E=.51 ; C=.54$ ) than did $\mathrm{Ss}$ of the RDL strain $(E=.37 ; C=.34)$. The difference between the strains was tested by computing the significance of the difference between correlated proportions and the $z$ of 2.51 was significant at better than the .05 level of confidence.

For the five Ss of each strain which were continued on the delayed intervals there was no strain difference for the first 11 days or for days 12-16.

Phase II. Since the performance of the two strains did not differ in Phase II the results are combined for the two strains and are shown in Fig. 1. An analysis is performed on each point and the obtained $\mathrm{z}$ values will be indicative merely of the relative magnitude of the difference. The $\mathrm{z}$ at $4 \mathrm{hr}$. is .64 (proportion correct responses: $\mathrm{E}=.80 ; \mathrm{C}=.73)$, the $\mathrm{z}$ at $6 \mathrm{hr}$. is $1.75(\mathrm{E}=.79$; $\mathrm{C}=.58)$, and the $\mathrm{z}$ at $8 \mathrm{hr}$. is $2.45(\mathrm{E}=.87 ; \mathrm{C}=.60)$. Thus, the trend in favor of the $E$ group is in the predicted direction-the difference being largest at the longest interval.

Using three trials a day it was not possible to continue beyond $8 \mathrm{hr}$. since the elapsed time between trial three of one day and trial one of the next would be less than $8 \mathrm{hr}$.

\section{Diseussion}

These results indicate that strychnine acts not only to enhance the learning performance on tasks which require immediate cue utilization but can also enhance the performance on a task which requires the utilization of a short-term memory trace. Since this difference first appears and is most striking at the longer intervals, the results cannot be interpreted simply in terms of drug enhancement of spontaneous alternation. Rather, they suggest that strychnine enhances the duration of perseverative neural processes underlying short-term memory. Also, these data indicate that strychnine does not merely serve to strengthen stereotyped response tendencies, since the task required the rats to vary their responses from trial to trial.

\section{Referenees}

BREEN, R. A., \& McGAUGH, J. L. Facilitation of maze learning with post-trial injections of picrotoxin. J. comp. physiol. Psychol., 1961, 54, 498-501.

McGAUGH, J. L., \& PETRINOVICH, L. Drug effects on learning and memory. Int. Rev. Neurobiol., 1965, 8, in press.

PETRINOVICH, L., \& BOLLES, R. Delayed alternation: evidence for symbolic processes in the rat. J. comp. physiol. Psychol., 1957, 50, 363-365.

RODERICK, T. H. Selection for cholinesterase activity in the cerebral cortex of the rat. Genetics, $1960,45,1123-1140$.

STRATTON, L. O., \& PETRINOVICH, L. Post-trial injections of an anti-cholinesterase drug and maze learning in two strains of rats. Psychopharm., 1963, 5, 47-54.

VERPLANCK, W. S., \& HAYES, J. R. Eating and drinking as a function of maintenance schedule. J. comp. physiol. Psychol., $1953,46,327-333$.

Notes

1. This research was supported by Research Grants MY3541, and MH10261 from the National Institute of Mental Health, United States Public Health Service and Research Grant GB-1612 from the National Science Foundation.

2. We thank Professor David Krech for supplying the rats from the Department of Psychology Animal Laboratory of the University of California, Berkeley. 